\title{
Impact of sustainable development goals on strategic planning in the Russian regions
}

\author{
Artem Mazein ${ }^{1, *}$ \\ ${ }^{1}$ Ural Institute of Management, Branch of Russian Presidential Academy of National Economy and \\ Public Administration, 66, 8 March st., 620144, Ekaterinburg, Russia
}

\begin{abstract}
Achievement by states of the Sustainable Development Goals proclaimed by the $\mathrm{UN}$ in 2015 requires appropriate governance. The most appropriate method is strategic planning. A large number of strategic planning documents have been adopted in Russian regions. The author notes that the words "plan," "forecast," "strategy," "program" are found in the names of 950 thousand legal acts of the regional and municipal levels. This is about $9 \%$ of their total. In this article, the author examines regional legislation for the inclusion of ideas on sustainable development. The author uses methods of analysis, synthesis, generalization, and systemstructural method. The study results confirm that the regulation of sustainable development is reflected primarily in strategic planning documents. The author shows that references to sustainable development in $88 \%$ of cases are found in strategic planning documents. Strategic planning documents are adopted following the federal law "On strategic planning in the Russian Federation". However, the article concludes that the approaches to the formation of strategic planning documents are different. The author demonstrates that similar strategic documents are adopted by various bodies and for different periods. For example, only 46 out of 85 regional development strategies have been adopted until 2030; the rest have different implementation dates. The author concludes that the difference in approaches is permissible, and the intersection of strategic measures in various documents of the same level must be timely excluded.
\end{abstract}

\section{Introduction}

The Sustainable Development Goals (SDGs), proclaimed by the United Nations in 2015, set goals for developing different states until 2030. Simultaneously, even during the SDGs formation, some states have already achieved specific target indicators [1]. Nevertheless, states needed to define those goals that had not yet been achieved.

In Russia, this is reflected in numerous legal documents. Today, legislation is one of the essential tools available to achieve long-term goals [2]. Simultaneously, legal acts of strategic planning (strategies, forecasts, plans, programs, and other documents) prevail in the regulation of sustainable development in Russia. It is believed that the use of the strategic planning method, in contrast to classical methods, allows, in addition to the goals of the activity, to determine the ways to achieve the desired result [3].

${ }^{*}$ Corresponding author: artemmazein@mail.ru 
The implementation of Federal Law No. 172-FZ dated June 28, 2014 "On Strategic Planning in the Russian Federation" makes the method of strategic planning essential for Russian management practice. Following this federal law, strategic planning documents are being developed in Russia within goal setting, forecasting, planning, and programming. This law defines in detail the procedure for the development and adoption of various strategic planning documents. The specifics of adopting strategic planning documents are determined not only at the federal but also at the regional and municipal levels.

Since regions and municipalities are developing several strategic planning documents (various strategies, forecasts, plans, programs), the number of such documents throughout the country is huge [4]. According to the Ministry of Finance of the Russian Federation, in 2020, there were 85 constituent entities of the Russian Federation and 20,846 municipalities in Russia. It is challenging to consolidate indicators from all strategic planning documents adopted on the Russian Federation's territory in practice.

For example, in Yekaterinburg, located on the Sverdlovsk Region territory, in 2020, the Strategic Development Plan of Yekaterinburg and 29 municipal programs were being implemented. In 2020, the Strategy for the socio-economic development and 29 state programs of the Sverdlovsk region, as well as one strategic planning document, were implemented on the territory of the Sverdlovsk region. At the federal level in 2020, 46 state programs and other strategic planning documents were implemented. More than 100 various programs are being implemented at the lower level (at the municipal level) in Yekaterinburg, not counting national projects, forecasts, sectoral strategies, and other documents.

Moreover, many activities within the framework of such programs aim to achieve the interests of city residents. In our opinion, residents find it very difficult to navigate such a variety of legal documents, which creates additional obstacles to successfully implementing their goals.

Moreover, many such documents create difficulties for management activities, including for monitoring the performance of individual indicators, for comparing indicators of different levels. Such a complex system of strategic planning documents confirms the idea that state and municipal planning is characterized by an incredibly complex structure, many conflicting tasks and interests [5].

Today, scientists continue to discuss the problem of choosing a methodology for constructing long-term forecasts [6]. This confirms the extreme complexity of strategic planning as a method of management activity.

In this regard, we assume that in the context of the implementation of Federal Law No. 172-FZ of June 28, 2014 "On Strategic Planning in the Russian Federation," only legal forms of strategic planning are uniquely defined, while conceptual approaches to defining strategies, plans, forecasts and other documents differ. In our opinion, such differences are due to a huge number of government entities at the federal, regional and municipal levels, which have a different status. We carried out this research to confirm this hypothesis and analyze the place of the SDGs in strategic planning in the Russian Federation.

\section{Materials and Methods}

Strategies for achieving the Sustainable Development Goals are formed under the influence of the well-established, generally recognized triune concept of sustainable development based on the interaction of economic, environmental, and social factors [7].

At present, researchers are expressing their views on the insufficient connection between environmental and socio-economic projects, which indicates the absence of a systematic approach to solving strategic issues [8]. The fragmentation of strategic documents may cause such a problem. 
To confirm or refute the thesis about the absence of a unified systematic approach to strategic planning, the current Russian legal acts were analyzed.

The Russian legal reference system "ConsultantPlus" served as the source for the analysis. In general, by the end of 2020, the "ConsultantPlus" system contains more than 370 thousand legal acts of the federal level and more than 10 million legal acts of the regional and municipal levels.

It should be noted that about 12.5 thousand legal acts of the federal level contain in the name one of the words "plan", "forecast", "strategy", "program", which reflect the content of strategic planning documents following Federal Law No. 172-FZ dated June 28, 2014 "On strategic planning in the Russian Federation". Similar words in names are found in 950 thousand legal acts of the regional and municipal levels. Thus, about $3.4 \%$ of federal acts and about $9 \%$ of regional and municipal acts were adopted to implement strategic planning.

The analysis of the array of strategic planning documents was carried out in several stages.

At the first stage, the President of the Russian Federation's Messages to the Federal Assembly for 2015 - 2020 were studied. The messages define the entire policy pursued in Russia. The Messages analysis aimed to identify everyday tasks for strategic planning and tasks for achieving the Sustainable Development Goals.

At the second stage, an analysis of legal acts was carried out to use provisions on the Sustainable Development Goals. A contextual search was carried out for keywords that reflect the content of all 17 SDGs. This search was carried out to confirm that the Sustainable Development Goals are more reflected in strategic planning documents.

At the third stage, among the identified strategic planning documents, the main regional strategic documents were identified and studied - the Strategies for the socio-economic development of the Russian Federation's constituent entities. All 85 strategies for the socioeconomic development of the constituent entities of the Russian Federation were analyzed from the point of view of the sources of their adoption (the sources of adoption are the authorities) and the point of view of their validity periods. We assumed that the regions' strategies are adopted by the authorities of different statuses, which indicates the absence of a unified approach among the regions. We also assumed that the regions' strategies are approved for different periods, the final dates of which differ from the deadlines for the implementation of the Sustainable Development Goals approved by the UN.

At the final stage, strategic planning documents were found for the Russian regions that are part of the Urals Federal District. We analyzed whether their validity dates correspond to the validity periods of other strategic planning documents. The directions of implementation of regional strategic planning documents and the Sustainable Development Goals were also compared. Besides, the directions of implementation of regional strategic planning documents were compared with each other. This analysis was carried out to establish the lack of unity of approaches to strategic planning at one level of government at the regional level.

In our opinion, such a systematic analysis of legislation is presentable since political and legal documents determine the ideological and organizational foundations of the development of the economy and public administration, and hence the implementation of the ideas of sustainable development [9].

In general, to process the search results in the "ConsultantPlus" legal system, the methods of analysis, synthesis, generalization and the system-structural method were used. 


\section{Results}

\subsection{Federal guidelines for strategic planning}

Strategic planning at the state level in Russia is based on applying the provisions of the Federal Law No. 172-FZ of June 28, 2014 "On strategic planning in the Russian Federation". This law establishes that the President of the Russian Federation's message to the Federal Assembly is the basis for determining the strategic goals and priorities of Russia's socio-economic development. The President delivers this Address every year.

Based on the President's Messages analysis, with which he addressed the deputies and senators after the United Nations proclaimed the Sustainable Development Goals, we found out the following.

The President made a direct mention of sustainable development only once in his Address of January 15, 2020. He noted that the UN's founding countries are responsible for the preservation and sustainable development of mankind. At the same time, the President of Russia noted that the present requires real action. However, these words were addressed primarily to foreign politicians and not to the Russian leadership.

An appeal to Russian politicians regarding the need to achieve strategic goals was made in the President's Address dated February 20, 2019. Then the President described the strategic goals as complex, requiring much effort. He noted that at that time, Russia had already identified strategic goals and objectives and established tools for achieving such goals.

The basic instruments for achieving the Sustainable Development Goals and other strategic objectives in Russia are strategic planning documents. Russian legislation defines the norms on the types of strategic planning documents and the procedure for their development. It is very important that Russian legislation also establishes a link between budgetary policy and strategic planning.

For example, following Article 8 of Federal Law No. 172-FZ of June 28, 2014 "On Strategic Planning in the Russian Federation," coordination of state and municipal strategic management and budgetary policy measures is one of the main tasks of strategic planning.

Among the central strategic planning documents are Russia's budget forecast, budget forecasts of the regions, and municipalities' budget forecasts. Also, in Russia, such a document is being developed as the Main direction of budgetary, tax, and customs-tariff policy. This document forms the basis for forming an essential strategic document - the Forecast of the Russian Federation's socio-economic development. Besides, budget legislation determines the procedure for financial support for the implementation of state and municipal programs.

Thanks to such a close connection between strategic goals and budgetary legislation, a basis is created for the effective achievement of the Sustainable Development Goals and other state objectives. At the same time, operational budgeting is an important tool for management activities [10].

It should be noted that the President is adopting other documents that are not listed in Federal Law No. 172-FZ of June 28, 2014 "On Strategic Planning in the Russian Federation", but contain a definition of strategic objectives. Such presidential decrees are essential for the development of various industries [11].

These documents include the following decrees:

- Decree of May 7, 2018 No. 204 "On national goals and strategic objectives for the development of the Russian Federation for the period up to 2024"; 
- Decree of July 21, 2020 No. 474 "On the national development goals of the Russian Federation for the period up to 2030".

Some believe that strategic objectives should be determined by laws, and not by the President, since laws take precedence. [12] We agree with this position, but we believe that due to the more complicated procedure for passing laws, it will be difficult to amend them if required.

At the same time, the establishment of strategic objectives by the President has a significant impact on the entire management system and the development of Russian regions since the established targets guide the regions.

\subsection{Integration of the Sustainable Development Goals into regional policy}

In general, regional legislation has become more frequent over the past 20 years to regulate sustainable development issues. In particular, in 2000, only 228 legal acts were adopted in the Russian regions, which directly referred to "sustainable development". In 2020, the number of mentions of sustainable development increased more than seven times and reached 1,671 mentions.

It is important to note that strategic planning documents often regulate sustainable development issues. We analyzed regional legal acts adopted in 2000 in 2016 (the year following the Sustainable Development Goals proclamation) and in 2020. Information on the total number of references to sustainable development and the number of references to sustainable development in strategic planning documents (strategies, plans, forecasts, programs) is presented in Table 1.

Table 1. References to sustainable development in legal acts

\begin{tabular}{|c|c|c|c|}
\hline & $\mathbf{2 0 0 0}$ & $\mathbf{2 0 1 6}$ & $\mathbf{2 0 2 0}$ \\
\hline All mentions & 228 & 2.197 & 1.671 \\
\hline $\begin{array}{c}\text { Mentions in } \\
\text { strategic } \\
\text { documents }\end{array}$ & 106 & 1.324 & 1.469 \\
\hline $\begin{array}{c}\text { Share of } \\
\text { references in } \\
\text { strategic } \\
\text { documents of the } \\
\text { total number }\end{array}$ & $46 \%$ & $60 \%$ & $88 \%$ \\
\hline
\end{tabular}

The information presented in Table 1 indicates the following:

- regional authorities stepped up their efforts to regulate sustainable development issues immediately after the proclamation of the Sustainable Development Goals;

- in recent years, issues of sustainable development have become more often regulated by strategic planning documents.

This information also confirms that sustainable development issues were managed long before the establishment of the SDGs. This experience allows Russian officials to base their planning on previous results. This approach is consistent with one of the models for achieving the Sustainable Development Goals that Huan speaks of [13]. However, Russian researchers consider this approach unproductive since the dynamics of changes in the external environment is not taken into account [14].

In general, there are three models for achieving the SDGs [13]:

- maintaining the existing productivity and subsequent growth;

- setting priorities for achieving a specific aspect of the SDGs;

- Simultaneously promoting progress on all aspects of the SDGs.

All three named models are reflected in Russian practice. 
Maintaining the current results occurs since in some regions, there are Development Strategies adopted long before the SDGs were approved and before the President of Russia established national development goals (for example, the Strategy for the Socio-Economic Development of the Udmurt Republic, approved in 2009).

Determination of priorities in achieving a particular aspect of the SDGs is also joint in Russian management practice. For example, the SDG "Sustainable Cities and Human Settlements" is most often mentioned in regional legislation, which occurs in regional legislation about 7 thousand times. The popularity of the idea of sustainable development of settlements is because special programs for the development of individual settlements are being developed in some regions. Such programs are aimed at realizing only one aspect of the SDGs. For instance:

- Sustainable development of out-of-town territories (Angarsk urban district of Irkutsk region);

- Sustainable development of rural settlements (Pervouralsky urban district of the Sverdlovsk region).

Simultaneous promotion of progress in achieving all aspects of the SDGs is ensured by adopting essential strategic planning documents (for example, multidimensional Strategy for the Socio-Economic Development of Regions).

\subsection{Strategic planning documents at the regional level}

The primary document of strategic planning at the regional level is the Strategy of socioeconomic development. In pursuance of the strategies, other documents are adopted, for example, state programs.

Figure 1 provides information on the completion date for implementing the existing regional strategies for socio-economic development.

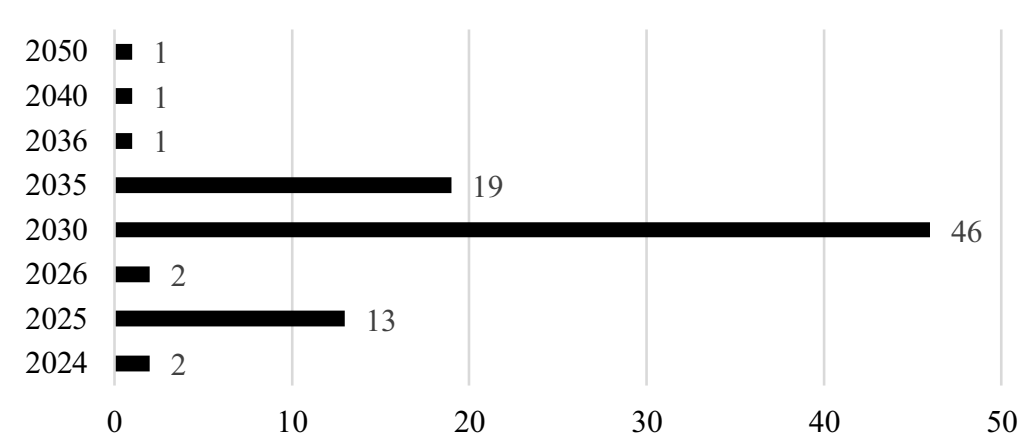

Fig. 1. Information on the number of strategies for the socio-economic development of Russian regions (with distribution by year of completion of implementation).

The information presented allows us to conclude the difference in approaches to the relationship between the implementation period of the SDGs, national development goals, and regional strategic planning. Only 46 regions identified 2030 as the last year of their strategies. It is 2030 that is defined as the year of completion of the SDGs.

At the same time, different regions differ in approaches to determining the body authorized to approve socio-economic development strategy. The analysis showed the following:

- in 36 regions, the strategy is approved by the legislative body of state power (in 30 cases by regional law, in 6 cases by decree, that is, by-law);

- in 2 regions, the strategy is approved by the highest official (Governor); 
- in 47 regions, the strategy is approved by the supreme executive body of state power of the constituent entity of the Russian Federation (in different regions they are called the Government, Administration, Cabinet of Ministers), while in 39 cases, the strategies were approved by resolution, in 8 cases - by order.

In some cases, even regional strategic documents do not relate to each other within one region. In some cases, within the same region, the time frame for implementing various strategic documents does not correspond to the time frame for the SDGs and the time frame for the implementation of the basic strategy.

For example, in the Sverdlovsk Region, the Strategy for Social and Economic Development is being implemented until 2030. At the same time, various government programs have different implementation periods that do not correspond to 2030. For instance:

- until 2024, the state program of the Sverdlovsk region "Information Society of the Sverdlovsk region until 2024" is being implemented;

- until 2025, the state program of the Sverdlovsk region is being implemented "Assistance in the creation of new places in the Sverdlovsk region in educational institutions for 2016 - 2025".

In addition to inconsistencies in the implementation period, there are individual activities between various strategic documents. For example, the Sverdlovsk region's state program "Increasing investment attractiveness" suggests that by 2018, 8 people should receive the title "Master of folk arts and crafts of the Sverdlovsk region." Simultaneously, following the Sverdlovsk region's state program, "Development of industry and science," this title should be received by 16 people before the beginning of 2018 .

\section{Discussion}

The study of Russian legislation for the inclusion of provisions on sustainable development showed that strategic planning prevails in the legal regulation of sustainable development. This method of management activity is actively used at the federal, regional, and municipal levels. However, in several cases, we see a lack of unity of approaches to strategic planning. This is manifested in the determination of different planning periods and the choice of different models for achieving the SDGs.

In some cases, problems in practice arise due to the intersection of the implemented activities. In many of these cases, timely legislation changes or the adoption of other legal acts are required [15].

In many cases, the intersection of individual strategic objectives is because various authorities are involved in management in different areas. Often, various authorities define different (unique) criteria and measurements of economic, environmental, and social conditions [16]. This gives rise to problems in legal regulation (collisions). However, we believe that various organs and the establishment of unique development criteria allow flexible and targeted regulation.

At the same time, the clever work of lawyers will help avoid conflicts, as well as establish a link between the SDGs, national development goals, regional development strategies, and individual state programs, which will ensure the full implementation of a systematic approach to solving strategic issues [8]. 


\section{Conclusion}

The strategic planning method is essential for management activities. This method allows for implementing activities to achieve various ambitious targets, including the Sustainable Development Goals.

The analysis showed that various legal documents are being developed to achieve the Sustainable Development Goals in Russia. Simultaneously, at the regional level, ideas about sustainable development are found more often in strategic planning documents (about $88 \%$ of references), less often in other documents.

Strategic planning documents are formally included in a single system, conditioned by the operation of the Federal Law No. 172-FZ of June 28, 2014 "On strategic planning in the Russian Federation". However, the approaches to forming the documents themselves and the determination of the links between them are different. We have shown that similar strategic documents are adopted for different periods by various competent authorities. In some cases, individual targets overlap.

This approach (different actors pay attention to different aspects of the problem) corresponds to one of the models for achieving the SDGs [13]. For this reason, such differences should not be criticized. It is crucial to eliminate the emerging collisions in time and prevent the emergence of new problems.

\section{References}

1. J.D. Moyer, S. Hedden, World Development 127 (2020) DOI: 10.1016/j.worlddev.2019.104749

2. C. Weatherup, S. Azam, European Journal of Public Health 30(1), i41-i42 (2020) https://academic.oup.com/eurpub/article/30/Supplement_1/i41/5835785

3. N. Vasylieva, Montenegrin Journal of Economics 15(1), 227-238 (2019)

4. S.A. Suspitsyn, Regional Research of Russia 10(2), 172-181 (2020) DOI:10.1134/S2079970520020148

5. A. Paucar-Caceres et al, Journal of the Operational Research Society 71(3), 363-380 (2020) DOI:10.1080/01605682.2019.1568840

6. M.T. Lukyanova et al, Scientifica 2020 (2020) DOI:10.1155/2020/9124641

7. S. Borodulina, T. Pantina, Advances in intelligent systems and computing 1258 (2021) DOI:10.1007/978-3-030-57450-5_68

8. N. Kosmacheva, G. Cherkasskaya, 18th International Multidisciplinary Scientific GeoConference SGEM 2018 18, 343-350 (2018) DOI:10.5593/sgem2018/5.3/S28.043

9. I. Grebnev, E3S Web of Conferences 208, 06008 (2020) DOI:10.1051/e3sconf/202020806008

10. V. Naseri, B. Kashanizadeh, F. Varposhti, 23rd Electrical Power Distribution Conference EPDC 2018, 63-68 (2018) DOI:10.1109/EPDC.2018.8536274

11. S.S. Vopilovskii, IOP Conference Series: Earth and Environmental Science 539 (2020) DOI:10.1088/1755-1315/539/1/012079

12. C.L. Strapazzon, C.B. Wandscheer, Universities and Sustainable Communities: Meeting the Goals of the Agenda 2030, 363-374 (2020) DOI:10.1007/978-3-03030306-8_21

13. Y. Huan et al, Science of the Total Environment 752 (2021) DOI:10.1016/j.scitotenv.2020.141875 
14. S.G. Karepova et al, Mediterranean Journal of Social Sciences 6(36), 357-364 (2015) DOI:10.5901/mjss.2015.v6n3s6p357

15. M. Mukhlynina, N. Vedysheva, Actual Problems of Ecology and Environmental Management: Cooperation for Sustainable Development and Environmental Safety (2020) https://doi.org/10.1051/e3sconf/202016905006

16. M. Milenković, A. Vaseashta, D. Vasović, Polish Journal of Environmental Studies 30(2), 1317-1323 (2021) DOI:10.15244/pjoes/124752 